\title{
Testicular rupture following rubber bullet trauma case report
}

\author{
Madison E. Kahle" ${ }^{1 \#}$, Kayla M. Hamann ${ }^{1 \#}$, Aliya A. Sakher ${ }^{1 \#}$, Erika A. Kaske ${ }^{1 \#}$, Travis Pagliara ${ }^{2}$, \\ Joseph J. Pariser ${ }^{1}$ \\ ${ }^{1}$ Department of Urology, University of Minnesota Medical School, Minneapolis, MN, USA; ${ }^{2}$ Department of Urology, Hennepin Healthcare, \\ Minneapolis, MN, USA \\ "These authors contributed equally to this work. \\ Correspondence to: Joseph J. Pariser, MD. Department of Urology, University of Minnesota Medical Center, 420 Delaware St. SE, Minneapolis, MN \\ 55455, USA. Email: jpariser@umn.edu.
}

\begin{abstract}
Following civil unrest during 2020, physicians began to notice a variety of injuries resulting from crowd control weapons. While prior research emphasized ocular trauma, genitourinary complications of injuries have yet to be investigated. A previously healthy 27 -year-old male presented to the emergency department due to sudden onset of severe left testicular pain following rubber bullet trauma. Physical exam showed extreme tenderness, abrasion, contusion, and edema of the left testicle with normal right testicle. Doppler ultrasound showed minimal blood flow to the superior pole with irregularity of the tunica albuginea. Surgery confirmed testicular rupture with a large tunical violation and extruded spermatic tubules. The testicle was thoroughly irrigated, non-viable tubules were debrided, and intraoperative ultrasound confirmed restoration of blood flow. Patient was discharged and instructed to follow-up should he face any fertility concerns in the future. Current crowd control guidelines state projectiles should be aimed at the lower abdomen or extremities; however, projectiles can cause testicular trauma which may lead to hypogonadism, infection, and psychological impact. Until there are changes to methods of crowd control, attendees should consider the use of athletic cups.
\end{abstract}

Keywords: Testicular rupture; crowd control weapon; case report

Submitted Mar 11, 2021. Accepted for publication Apr 25, 2021.

doi: $10.21037 / \mathrm{tau}-21-213$

View this article at: https://dx.doi.org/10.21037/tau-21-213

\section{Introduction}

Following the George Floyd Protests in 2020, many physicians noted injuries from crowd control weapons and multiple medical societies called for the discontinued use of these weapons in protests (1-4). Much of the crowd control weapons research has focused on eye trauma; however, little is known on the urological trauma sustained from these weapons (5-7). While we identified many reports in the media, we were unable to identify any urological injury case reports in the medical literature $(8,9)$. At our institution, we identified one surgical case. Here, we will describe the case of a 27-year-old male who suffered a traumatic left testicular rupture due to a rubber bullet while attending a demonstration following the format of the CARE reporting checklist (available at http:// dx.doi.org/10.21037/tau-21-213).

\section{Case presentation}

A previously healthy 27 -year-old male presented to the emergency department immediately after attending a racial injustice protest. The patient had been filming the events of the protest when he experienced a sudden onset of severe pain in the left testicle. Upon examination, he realized his scrotum had been struck by a rubber bullet fired by law enforcement. The patient was transported to the Emergency Department. Physical exam showed an abrasion and contusion over the left hemiscrotum with edema and extreme tenderness of the left testicle, with normal right testicle. Initial formal ultrasound showed concern for intratesticular hematoma and edema of the left epididymis (Figure 1). Doppler ultrasound indicated decreased blood flow to the left epididymis. Urology was urgently consulted. 


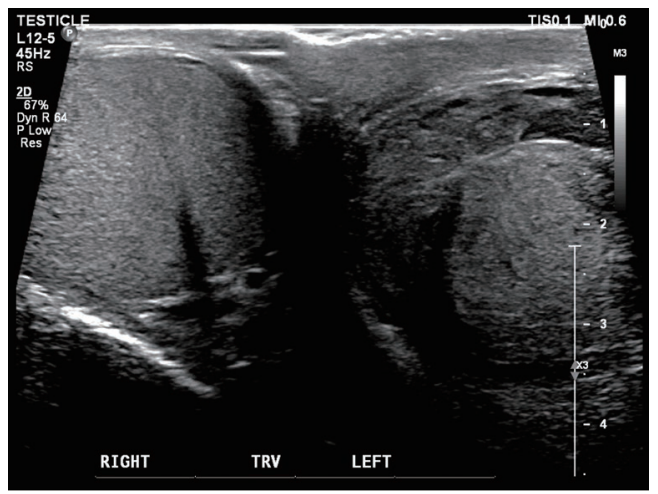

Figure 1 Pre-operative ultrasound. Irregularity of the tunica albuginea is highly concerning for testicular rupture, and there is also a peritesticular hematoma present.

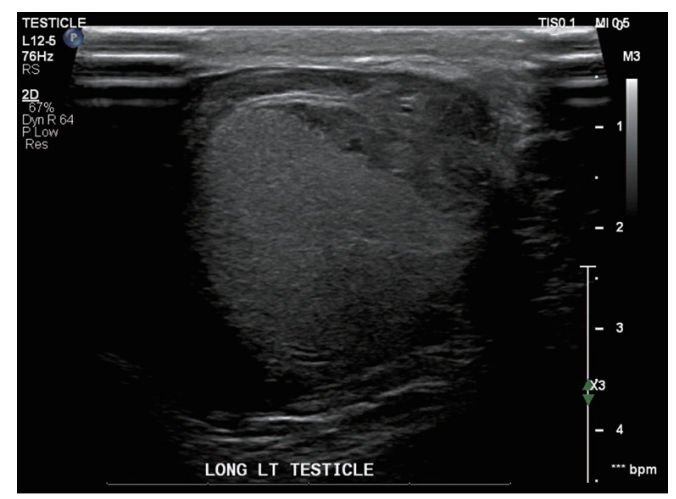

Figure 2 Pre-operative ultrasound. Areas of heterogeneous decreased echogenicity within the left testicular parenchyma consistent with intratesticular hematoma, a small portion of the superior pole of the left testicle appears perfused, remainder the testicle appears nonperfused.

The patient was subsequently admitted for observation. Repeat ultrasound after admission was concerning for devitalization of the left testicle with minimal blood flow seen to the superior pole (Figure 2). Irregularity of the tunica albuginea was also observed, consistent with testicular rupture. Debridement and potential orchiectomy were discussed with the patient. The patient was highly concerned about the potential impacts of surgery on his fertility, and initially declined surgical intervention. Following further discussion with the patient and addressing all concerns, he agreed to surgical intervention. Patient was taken to the operating room and underwent surgical exploration. The left testicle was notable for a large tunical violation with extruded spermatic tubules, confirming rupture. The testicle was thoroughly irrigated, and nonviable tubules were debrided. Intraoperative ultrasound demonstrated restoration of blood flow following repair, eliminating the need for orchiectomy. On follow-up, postoperative day 24 , the patient was doing well with minor testicular pain and edema but no additional concerns. He was instructed to follow-up should he face any fertility concerns in the future, though it likely would not be a problem. All procedures performed in studies involving human participants were in accordance with the Declaration of Helsinki (as revised in 2013). Written informed consent was obtained from the patient.

\section{Discussion}

The world has seen an increase in social and political demonstrations, many of which have required police or military response (5,10-12). Given this, healthcare providers are treating significantly more patients with injuries related to crowd control weapons. Current crowd control guidelines state that projectiles (i.e., rubber bullets, beanbags) should be aimed only at the lower abdomen or extremities (13). These guidelines are intended to protect the head, eyes, and neck from life threatening and permanently disabling injuries. However, disabling injuries can also result from strikes to the pelvis. This case demonstrates how projectiles used for crowd control that are fired at the lower abdomen/ extremities can lead to genital injury, in this case testicular injury. Genitourinary trauma can negatively impact a patient's sexual function, fertility and psychological wellbeing. However, given that this was a single report, further research should be conducted following the use of crowd control weapons to better understand the long-term implications of injuries. Until there is re-examination of current guidelines on the use of crowd control weapons, those attending protests should consider the use of athletic cups. Ideally, safer methods of crowd control should be employed in order to protect patients from harm.

\section{Acknowledgments}

Funding: None.

\section{Footnote}

Reporting Checklist: The authors have completed the CARE reporting checklist. Available at http://dx.doi.org/10.21037/ 
tau-21-213

Peer Review File: Available at http://dx.doi.org/10.21037/ tau-21-213

Conflicts of Interest: All authors have completed the ICMJE uniform disclosure form (available at http://dx.doi. org/10.21037/tau-21-213). The authors have no conflicts of interest to declare.

Ethical Statement: The authors are accountable for all aspects of the work in ensuring that questions related to the accuracy or integrity of any part of the work are appropriately investigated and resolved. All procedures performed in studies involving human participants were in accordance with the Declaration of Helsinki (as revised in 2013). Written informed consent was obtained from the patient.

Open Access Statement: This is an Open Access article distributed in accordance with the Creative Commons Attribution-NonCommercial-NoDerivs 4.0 International License (CC BY-NC-ND 4.0), which permits the noncommercial replication and distribution of the article with the strict proviso that no changes or edits are made and the original work is properly cited (including links to both the formal publication through the relevant DOI and the license). See: https://creativecommons.org/licenses/by-nc-nd/4.0/.

\section{References}

1. Statement on Rubber Bullets for Crowd Dispersion. Published June 4, 2020. Accessed December 16, 2020. Available online: https://www.aao.org/newsroom/newsreleases/detail/statement-on-rubber-bullets-crowddispersion

2. Ifantides C, Christopher KL, Deitz GA, et al. Ophthalmic Injuries by Less-Lethal Kinetic Weapons During the US George Floyd Protests in Spring 2020. JAMA Ophthalmol 2021;139:242-4.

3. Kaske EA, Cramer SW, Pena Pino I, et al. Injuries from

Cite this article as: Kahle ME, Hamann KM, Sakher AA, Kaske EA, Pagliara T, Pariser JJ. Testicular rupture following rubber bullet trauma case report. Transl Androl Urol 2021;10(8):3529-3531. doi: 10.21037/tau-21-213
Less-Lethal Weapons during the George Floyd Protests in Minneapolis. N Engl J Med 2021;384:774-5.

4. Olson KA, Haselden LE, Zaunbrecher RD, et al. Penetrating Injuries from "Less Lethal" Beanbag Munitions. N Engl J Med 2020;383:1081-3.

5. Lartizien R, Schouman T, Raux M, et al. Yellow vests protests: facial injuries from rubber bullets. Lancet 2019;394:469-70.

6. Coleman AL, Williams GA, Parke DW 2nd. Ophthalmology and "Rubber Bullets". Ophthalmology 2020;127:1287-8.

7. Shot in the Head. Accessed December 16, 2020. Available online: https://phr.org/our-work/resources/shot-in-thehead/

8. Wigglesworth A. Community organizer who trains police on bias injured by rubber bullet during protest. Los Angeles Times. Available online: https://www.latimes.com/ california/story/2020-06-06/community-organizer-shotby-rubber-bullet-during-protest. Published June 7, 2020. Accessed February 1, 2021.

9. Granda C. Protester calls for changes at LAPD, says he was shot at point-blank range with rubber bullets. KABC-TV. Published June 25, 2020. Accessed February 1, 2021. Available online: https://abc7.com/protestershot-by-rubber-bullet-in-testicles-demands-changes-atlapd/6268362/

10. Heisler M, Hampton K, McKay D. Dangerous use of crowd-control weapons against medics and protesters in Portland, OR. Lancet 2020;396:e59-60.

11. Haar RJ, Iacopino V, Ranadive N, et al. Death, injury and disability from kinetic impact projectiles in crowd-control settings: a systematic review. BMJ Open 2017;7:e018154.

12. Haar RJ, Iacopino V, Ranadive N, et al. Health impacts of chemical irritants used for crowd control: a systematic review of the injuries and deaths caused by tear gas and pepper spray. BMC Public Health 2017;17:831.

13. Commissioner UNFHRO of TH, United Nations for Human Rights Office of the High Commissioner. United Nations Human Rights Guidance on Less-Lethal Weapons in Law Enforcement 2020. doi:10.18356/5c14b275-en. 